\title{
SISTEM INFORMASI PENJUALAN KAOS BERBASIS WEB PADA DISTRO AZIDAN COLLECTION
}

\author{
Angga Ardiansyah ${ }^{1}$, Eva Argarini Pratama ${ }^{2}$, Corie Mei Hellyana ${ }^{3}$, Khaerul Wildan ${ }^{4}$ \\ ${ }^{1}$ STMIK Nusamandiri Jakarta, ${ }^{2,3,4}$ Universitas Bina Sarana Informatika \\ e-mail: ${ }^{1}$ angga.axr@nusamandiri.ac.id. ${ }^{2}$ eva.eap@bsi.ac.id, ${ }^{3}$ corie.cma@bsi.ac.id \\ ${ }^{4}$ khaerulw149793@bsi.ac.id
}

\begin{abstract}
Azidan Collection distributions have several shortcomings in order to support the process of selling goods. The current sales are only limited to consumers coming directly to the store selecting goods and paying, to promote products that are on Azidan distributions to consumers already using social media including through BBM and Facebook friendship media media. Sales using social media systems are still lacking, because customer coverage is only limited to using social media, so sales transactions are limited. The Sales Website on the Azidan Collection Distro which has functions, among others. Build an e-commerce application to help management of the Azidan Collection in making long-distance transactions. Building an e-commerce transaction application to help consumers make a T-shirt purchase on the Azidan Collection Distro. This information system is equipped with facilities that can facilitate customers in making payment transactions through account transfers.
\end{abstract}

\section{Keywords - Information System, T-Shirt Sales, Azidan Collection Distro}

Abstrak - Distro Azidan Collection mempunyai beberapa kekurangan dalam rangka menunjang proses penjualan barang. Penjualan yang saat ini dilakukan hanya sebatas konsumen datang langsung ke toko memilih barang dan membayar, untuk mempromosikan produk yang ada di Distro Azidan ke konsumen sudah menggunakan media sosial di antaranya melalui BBM dan media situs pertemanan facebook. Penjualan dengan menggunakan sistem media sosial dirasa masih kurang, karena cakupan customer hanya sebatas yang menggunakan media sosial saja, sehingga transaksi penjualan menjadi terbatas. Website Penjualan pada Distro Azidan Collection yang memiliki fungsi antara lain. Membangun aplikasi e-commerce untuk membantu manajemen Distro Azidan Collection dalam melakukan transaksi jarak jauh. Membangun aplikasi transaksi e-commerce untuk membantu dan memberi wawasan pada konsumen dalam melakukan pembelian Kaos di Distro Azidan Collection. Sistem informasi ini dilengkapi dengan fasilitas yang mampu mempermudah customer dalam melakukan transaksi pembayaran yang melalu transfer rekening.

\section{Kata kunci - Sistem Informasi, Penjualan Kaos, Distro Azidan Collection}

\section{A. PENDAHULUAN}

Saat ini perkembangan teknologi telah semakin canggih dan maju, seperti halnya perkembangan internet. Keberadaan internet dan perkembangan teknologi saat ini telah menjadi faktor yang sangat penting dalam pekerjaan manusia di banyak bidang, karena dengan adanya internet dapat memudahkan manusia dalam mencari informasi dengan waktu yang relatif lebih singkat. Dengan menggunakan kecangggihan teknologi informasi, hal ini menjadi fenomena dan peluang bisnis yang besar, salah satunya dengan membangun dan mengembangkan suatu website. Dalam bidang penjualan, website dapat dijadikan sebagai media atau sarana untuk melaksanakan transaksi jual beli barang ataupun produk yang membuat transaksi penjualan dapat dilakukan dengan waktu yang relatif singkat walau terhalang oleh jarak berjauhan.

Distro Azidan merupakan salah satu usaha dalam bidang fashion. Untuk mempromosikan produk yang ada di Distro Azidan ke konsumen, Distro Azidan sudah memanfaatkan media sosial seperti bbm, facebook, dan instagram. Akan tetapi untuk transaksi pemesanan di lakukan dengan cara konsumen langsung datang ke toko. Dengan hanya mengandalkan sistem penjualan dari media sosial facebook, bbm, dan instagram di rasa masih kurang dalam memperbanyak dan memperluas tingkat penjualan barang.

Dengan adanya permasalahan yang di hadapi oleh Distro Azidan dalam melakukan promosi karena keterbatasan media promosi, 
sehingga penulis berencana untuk mencari solusi yang tepat dalam menangani permasalahan tersebut. Dengan adanya perkembangan teknologi saat ini, salah satunya dengan menggunakan website agar pemasaran lebih luas dan promosi lebih efektif. Kemudahan untuk transakasi jual beli tanpa adanya batasan waktu dan tempat, dan memudahkan pengelola distro Azidan dengan mengelola data member maupun laporan transaksi.

\section{B. TINJAUAN PUSTAKA}

\section{Sistem Informasi}

Sistem dapat diartikan sebagai kumpulan dari elemen-elemen atau unsur-unsur berupa data, jaringan dari prosedur-prosedur yang saling berhubungan, sumber daya manusia, teknologi baik hardware maupun software yang saling berinteraksi sebagai satu kesatuan untuk mencapai tujuan atau sasaran tertentu yang sama(Maniah \& Hamidin, 2017).

Menurut (Darmawan \& Fauzi, 2013) sistem sebagai kumpulan/grup dari bagian komponen apapun baik fisik yang saling berhubungan satu sama lain dan bekerja sama secara harmonis untuk mencapai satu tujuan.

Sedangkan Informasi merupakan hasil dari pengolahan data, akan tetapi tidak semua hasil dari pengolahan tersebut bisa menjadi informasi, hasil pengolahan data yang tidak memberikan makna atau arti serta tidak bermanfaat bagi seseorang bukanlah merupakan informasi bagi orang tersebut (Darmawan \& Fauzi, 2013).

\section{E-Commerce}

e-commerce merupakan jenis website yang pada umumnya untuk melakukan aktivitas jual-beli produk atau jasa melalui dunia maya. Ada beberapa fitur atau layanan yang wajid dimiliki jenis website ini seperti katalog produk atau jasa, informasi stok produk, keranjang belanja, riwayat belanja, testimoni, customer service, dan lain lain (Rerung, 2018).

\section{METODE PENELITIAN}

Menurut Rosa dan Shalahudin (2013:28) dalam (Dermawan \& Hartini, 2017) menyimpulkan bahwa "Model SDLC air terjun(waterfaal) sering juga disebut model sekuensial linier (sequential linier) atau alur hidup klasik (classic life cicle)". Model air terjun menyediakan suatu pendekatan alur hidup dari perangkat lunak secara sekuensial atau berurutan yang dimulai dari analisis, desain, pengodean, pengujian dan tahap pendukung (support). Berikut adalah gambar model air terjun :

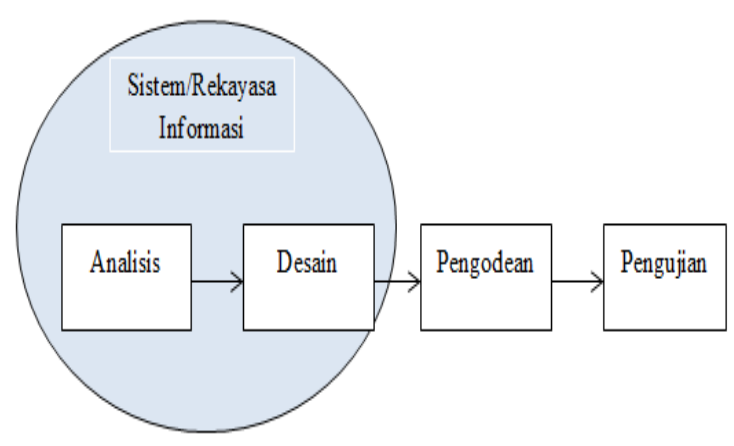

Gambar 1. Ilustrasi Model Waterfall.

\section{HASIL DAN PEMBAHASAN}

1. Analisis kebutuhan pengguna a. Hak Akses Admin

1) Admin dapat mengelola tampilan web user dan admin.

2) Admin dapat mengelola seluruh data seperti melakukan input, edit, delete, update.

3) Admin dapat melihat data user atau konfirmasi dari member.

b. Hak Akses Member

1) Member dapat melihat halaman menu beranda, kontak, produk atau detail produk, cara pesan tanpa harus melakukan registrasi dahulu.

2) Member dapat melakukan input komentar pada halaman menu kontak.

3) Member dapat melakukan login dengan memasukan email dan password yang telah terdaftar.

4) Member dapat mengelola data pada halaman edit akun,chekout dan keranjang setelah melakukan login.

5) Member dapat melakukan pemesanan produk, transaksi setelah melakukan login.

\section{c. Hak Akses user}

1) User dapat melihat halaman menu beranda, kontak, produk atau detail produk, cara pesan tanpa harus melakukan registrasi dahulu.

2) User harus login dahulu jika ingin membeli produk.

3) User dapat melakukan input data pada halaman menu registrasi untuk kebutuhan login member agar dapat melakukan pembelian produk dan transaksi. 
2. Analisis Kebutuhan Sistem

a. Sistem menyediakan form registrasi untuk pengunjung web agar terdaftar sebagai user dan dapat melakukan pemesanan produk.

b. Sistem Menyediakan layanan transaksi pembelian produk.

c. Sistem memberikan informasi tentang cara berbelanja dan cara pembayaran.

d. Setelah melakukan transaksi pembelian produk, user dapat mengisi form konfirmasi pembayaran.

3. Rancangan Antar Muka

a. Rancangan Antar Muka Halaman Index(Beranda)

Index adalah halaman depan dari semua halaman yang ada pada tampilan website. Halaman ini juga bisa disebut sebagai halaman pembuka karena pada saat website dibuka maka tampilan inilah yang akan muncul terlebih dahulu. Rancangan halaman index(beranda).

b. Rancangan Antar Muka Halaman Tentang Kami

Halaman tentang kami dirancang untuk menampilkan tentang toko Azidan Collection.

c. Rancangan Antar Muka Halaman Cara Order

Halaman cara order dirancang untuk menampilkan tahap tahap cara pemeblian produk pada website ini.

d. Rancangan Antar Muka Halaman Semua Produk

Halaman semua produk pada website ini berisi tentang data - data barang yang dijual. Data tersebut mencakup nama barang, harga barang, dan juga dilengkapi gambar dari barang yang dijual tersebut.

e. Rancangan Antar Muka Halaman Kontak

Halaman Kontak merupakan halaman yang dirancang untuk memberikan informasi kontak, agar pengunjung bisa menghubungi pemilik website. khususnya bagi para member yang berbelanja.

f. Rancangan Antar Muka Halaman Login Member

Halaman login member dirancang untuk pengguna masuk ke dalam ruangan member, sehingga pengguna dapat melakukan transaksi pembelian. g. Rancangan Antar Muka Halaman Beranda Member

Halaman home member adalah halaman awal yang terdapat pada ruang member setelah member berhasil login pada login member.

h. Rancangan Antar Muka Halaman Akun Saya

Halaman akun saya adalah halaman yang berisi data member, member dapat mengubah data melalui akun saya.

i. Rancangan Antar Muka Halaman Keranjang belanja

Halaman keranjang belanja adalah halaman yang berisi detail barang yang sudah dibeli oleh member.

j. Rancangan Antar Muka Halaman Konfirmasi Pembayaran

Halaman konfirmasi pembayaran adalah halaman member yang di gunakan untuk melakukan konfirmasi pembayaran setelah member melakukan pembayaran

k. Rancangan Antar Muka Halaman Cekout

Halaman Cekout adalah halaman member yang keluar setelah member melakukan belanja, untuk mengetahui total belanja dan dihalaman cekout member memilih kota tujuan dan paket jasa kirim.

I. Rancangan Antar Muka Halaman beranda admin

Halaman beranda admin adalah halaman awal yang terdapat pada ruang administrator setelah admin melakukan login.

m. Rancangan Antar Muka Halaman kategori produk

Halaman ini berfungsi menampilkan dan mengelola kategori produk dalam bentuk tabel. Terdapat tombol tambah data yang berfungsi untuk menambah kategori produk baru. Edit yang berfungsi untuk mengubah nama kategori dan tombol hapus untuk menghapus kategori produk.

n. Rancangan Antar Muka Halaman Data produk

Halaman ini berfungsi menampilkan dan mengelola data produk dalam bentuk tabel. Terdapat tombol tambah data yang berfungsi untuk menambah data produk baru. Edit yang berfungsi untuk mengubah data produk dan tombol hapus untuk menghapus data produk

o. Rancangan Antar Muka Halaman kota 
Halaman ini berfungsi menampilkan dan mengelola halaman kota dalam bentuk tabel. Terdapat tombol tambah data yang berfungsi untuk menambah kota baru. Edit yang berfungsi untuk mengubah nama kota dan tombol hapus untuk menghapus kota. Tombol cari kota berfungsi untuk mencari nama kota.

p. Rancangan Antar Muka Halaman jasa ongkir

Halaman ini berfungsi menampilkan dan mengelola halaman jasa ongkir dalam bentuk tabel. Terdapat tombol tambah data yang berfungsi untuk menambah jasa ongkir baru. Edit yang berfungsi untuk mengubah nama jasa dan tombol hapus untuk menghapus jasa.

q. Rancangan Antar Muka Halaman tarif ongkir

Halaman ini berfungsi menampilkan dan mengelola halaman tarif ongkir dalam bentuk tabel. Terdapat tombol tambah data yang berfungsi untuk menambah tarif ongkir baru. Ubah yang berfungsi untuk mengubah halaman tarif ongkir dan tombol hapus untuk menghapus tarif ongkir. Tombol cari tarif berfungsi untuk mencari tarif melalui nama jasa dan kota.

r. Rancangan Antar Muka Halaman pelanggan

Halaman ini berfungsi menampilkan dan mengelola halaman pelanggan dalam bentuk tabel. Terdapat cari pelanggan yang berfungsi untuk mencari pelanggan. Ubah yang berfungsi untuk mengubah halaman pelanggan.

s. Rancangan Antar Muka Halaman pesanan/order

Halaman ini berfungsi menampilkan pesanan baru dari member.

t. Rancangan Antar Muka Halaman konfirmasi

Halaman ini dirancang untuk admin agar bisa melihat member yang sudah melakukan konfirmasi.

u. Rancangan Antar Muka Halaman laporan data produk

Halaman ini dirancang untuk admin agar admin dapat mengetahui laporan data produk.

v. Rancangan Antar Muka Halaman laporan data pelanggan
Halaman ini dirancang untuk admin agar admin dapat mengetahui laporan data pelanggan.

w. Rancangan Antar Muka Halaman laporan penjualan

Halaman ini dirancang untuk admin agar admin dapat mengetahui laporan penjulan produk.

x. Rancangan Antar Muka Halaman data admin

Halaman ini dirancang untuk menampilkan data admin. Terdapat tombol ubah yang berfungsi untuk mengubah nama admin dan hapus yang berfungsi untuk menghapus data admin.

y. Rancangan Antar Muka Halaman Komentar

Halaman ini dirancang untuk menampilkan komentar dari user atau member.

4. Rancangan Basis Data

a. Entity Relatonship Diagram (ERD)

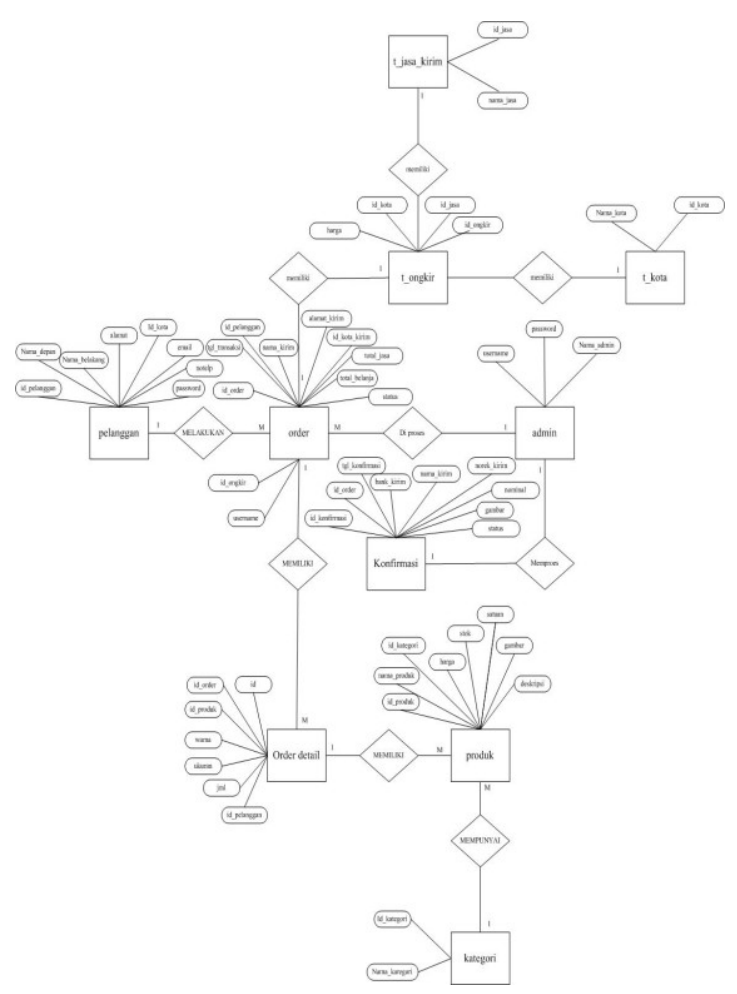

Gambar 2. Entity Relatonship Diagram (ERD) 
b. Logical Record Structure (LRS)

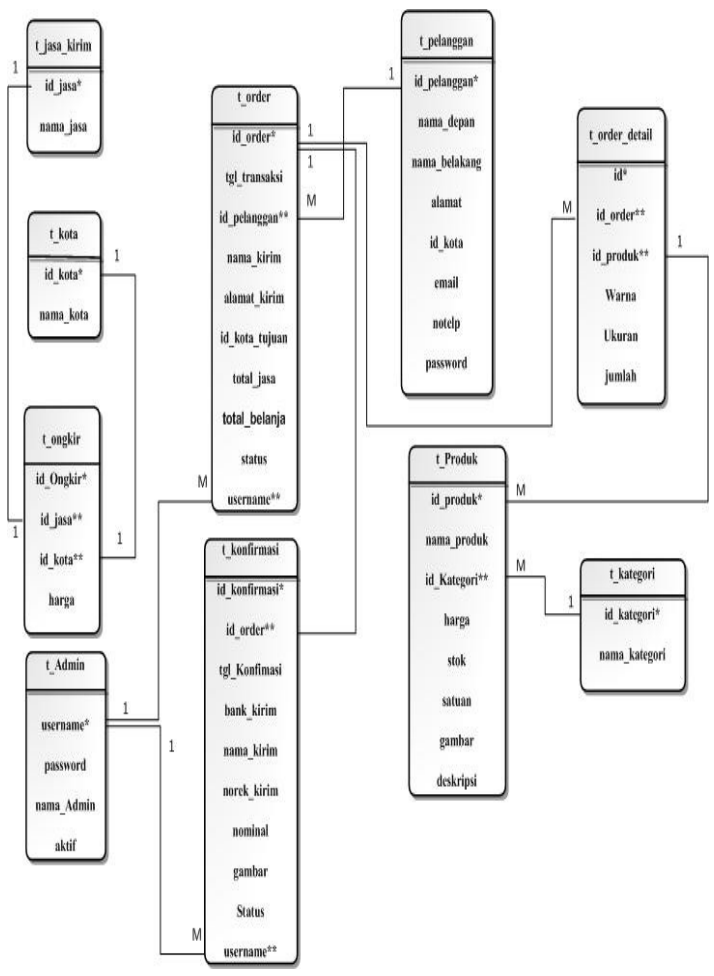

Gambar 3. Logical Record Structure (LRS)

5. Implementasi

a. Tampilan Halaman Beranda User

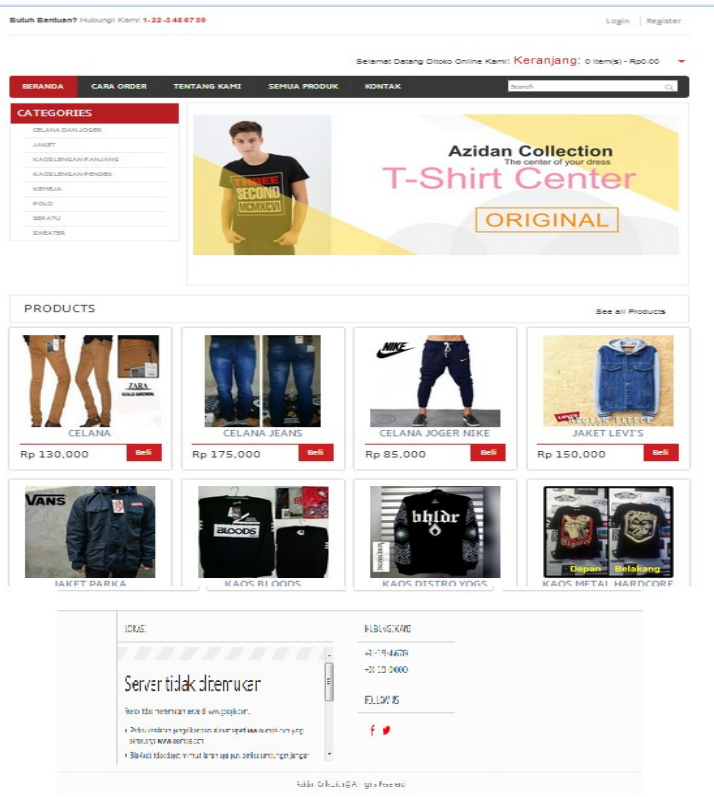

b. Tampilan halaman Semua Produk

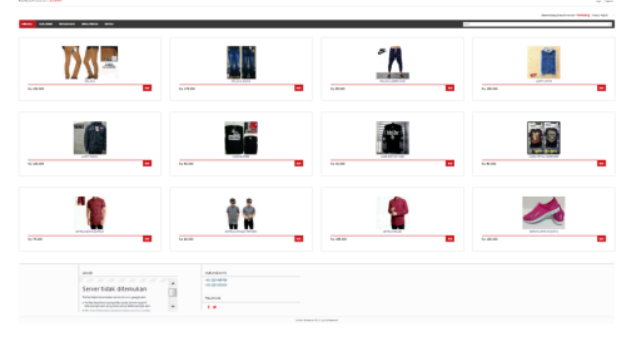

Gambar 4. Tampilan Halaman Semua Produk

c. Tampilan Halaman Keranjang Belanja

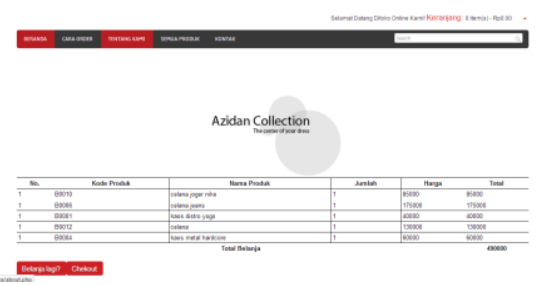

Gambar 5. Tampilan Halaman Keranjang Belanja

d. Tampilan Halaman Cekout

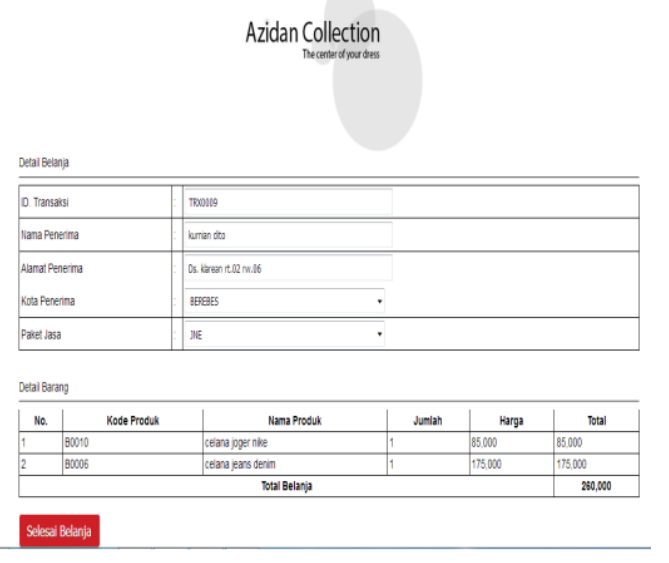

Gambar 6.Tampilan Halaman Cekout

Gambar 3. Tampilan Halaman Beranda User 


\section{E. KESIMPULAN}

Berdasarkan pembahasan yang ada dalam penelitian ini, maka dapat di simpulkan bahwa

a. Aplikasi E-comerce ini merupakan sebuah aplikasi yang sangat bermanfaat dalam bisnis perdagangan sebagai bentuk perkembangan tekhnologi informasi.

b. Dengan adanya Website E-commerce konsumen dapat melihat dan memesan produk tanpa harus datang langsung ke toko, tetapi cukup dengan mengakses situs resmi toko tersebut melalui media intrnet.

c. Aplikasi penjualan atau E-comerce ini dapat menjadi media promosi dalam memperluas jangakauan informasi memperkenalkan produk - produk yang ada melalui Website E-commerce Azidan Collection.

Dengan adanya Website E-commerce ini dapat meningkatkan efektifitas dan efesiensi segi tenaga, waktu dan biaya seperti web hosting yang tidak terlalu mahal dan mengurangi biaya operasional lainya.

\section{DAFTAR PUSTAKA}

Darmawan, D., \& Fauzi, K. N. (2013). Sistem Informasi Manajemen. (A. Kamsyach, Ed.). Bandung: PT REMAJA ROSDAKARYA.

Dermawan, J., \& Hartini, S. (2017). IMPLEMENTASI MODEL WATERFALL

PADA PENGEMBANGAN SISTEM INFORMASI PERHITUNGAN NILAI MATA PELAJARAN BERBASIS WEB PADA SEKOLAH DASAR AL-AZHAR SYIFA BUDI JATIBENING. Paradigma, 19, 143. Retrieved from https://ejournal.bsi.ac.id/ejurnal/index.ph p/paradigma/article/download/2131/1707

Maniah, \& Hamidin, D. (2017). Analisis dan Perancangan Sistem Informasi. yogyakarta: Deepublish.

Rerung, R. R. (2018). E-Commerce Menciptakan Daya Saing Melalui Teknologi Informasi. yogyakarta: Deepublish. 